\title{
«Derecho, poder y libertad» a propósito de las batallas por la autonomía jurisdiccional entre las Audiencias del Cusco y Charcas $(1820-1825)^{1}$
}

\author{
por \\ Núria Sala i Vila \\ Universitat de Girona \\ nuria.sala@udg.edu
}

A partir de 1820 y tras la invasión de San Martín, el sistema judicial peruano tuvo que adecuarse a la desaparición de facto de la Audiencia de Lima y al modelo diseñado por la Constitución de 1812 y el Reglamento de las Audiencias y Juzgados de primera instancia del 9 de octubre de 1812. El artículo analiza tal proceso y las tensiones generadas cuando las Audiencias Nacionales de Cusco y Charcas hubieron de resolver problemas de procedimiento, pero sobre todo se ahonda en los debates y actores, abogados fundamentalmente, que conformaron la cultura jurídica hispana durante el Trienio Liberal en el virreinato del Perú, asumiendo que tal realidad trascendió en la construcción nacional del Perú y Bolivia.

Palabras Clave: Trienio Liberal; Perú; Cultura Jurídica; Audiencia Nacional del Cusco; Audiencia Nacional de Charcas.

Una de las convenciones historiográficas al uso es aquella que nos lleva a marcar en la línea del tiempo un parteluz, un punto de quiebre o una coyuntura más o menos determinante en el devenir social. En múltiples casos los consensos son más o menos fáciles de ser interiorizados sin más, en otros todo deviene una gran complejidad, como la vida misma. Uno de tales procesos es el que tendría entre uno de tantos hitos las independencias de Bolivia y el Perú. Ambos territorios coloniales vivieron, al menos desde fines de la década

\footnotetext{
${ }^{1}$ Investigación realizada dentro del proyecto HAR 2014-54891-P, financiado por el Ministerio de Economía y Competitividad.
} 
de 1760 , cambios trascendentes en su cultura política, cuando se sucedieron una serie de modificaciones sustanciales al statu quo colonial precedente en el marco de las reformas borbónicas y los proyectos liberales: nuevas demarcaciones administrativas y judiciales -virreinato del Río de La Plata (1776), Audiencia del Cusco (1788), sistema de intendencias (post1784)-; políticas económicas, fiscales y administrativas lesivas a los intereses criollos; altos niveles de contestación e insurgencia con un momento crítico en la Gran Rebelión (1780-3); reordenación de la esfera religiosa y educativa tras la expulsión de los jesuitas (1767); crisis de la Monarquía hispánica y respuestas juntistas; influencia de las revoluciones liberales y/o republicanas hispánica, norteamericana, francesa y haitiana; un largo ciclo de campañas militares, procesos constituyentes, seguidos tras las independencias de facto (1824-5) de un largo periodo de tensiones al no alcanzarse consensos en los modelos políticos o territoriales.

No pretendemos proponer periodificación alguna, más bien ahondar en la multicausalidad y en la importancia de las dinámicas propias de la historia vivida en los Andes en el paso de Colonia a República, hasta alcanzar el consenso republicano en torno a 1824-25, aunque el relativo a la organización territorial sólo se resolvería entre la Confederación Perú-boliviana (1836-39) y la batalla de Ingavi con la derrota del proyecto anexionista peruano del general Agustín Gamarra ${ }^{2}$. En las siguientes páginas analizaremos un episodio que complejiza aún más el proceso o lo clarifica, según como se mire: el enfrentamiento entre las Audiencias de Cusco y Charcas a raíz de la desaparición de facto de la Audiencia de Lima, tras la invasión del general José de San Martín y el repliegue a la sierra del virrey José de La Serna. En el trasfondo del episodio se situó el proceso de adecuación de los procedimientos judiciales a los dictados de la Constitución de 1812 y del Reglamento de las Audiencias y Juzgados de primera instancia de 9 de octubre de 1812. Ello se abordará combinando un acercamiento institucional con el rescate de los actores y su proyección profesional y política. Se analizará su trascendencia en relación a: 1) los cambios que comportó la erección de la Audiencia Nacional del Cusco en audiencia territorial, subordinando en la práctica a la de Charcas; 2) la adecuación de la nueva legislación respecto a la vigente por entonces; 3) la actuación de jueces y asesores legales imbuidos del espíritu legal liberal; 4) y, por último, al grado de implicación de éstos en el devenir jurídico y/o político de los proyectos liberales que se dirimieron en el sur del Perú y Bolivia durante sus tempranas repúblicas.

\footnotetext{
${ }^{2}$ En tal sentido véase Irurozqui, 2015: 60-91.
} 
Seguimos sin contar con un balance global y comparativo de las transformaciones acaecidas en la cultura jurídica en Perú y Bolivia entre Colonia y República, en parte debido al peso de las historias nacionales o bien, a que se ha priorizado la interrelación o influjo entre Charcas y el virreinato del Río de La Plata (1776-1810). Desde la óptica de los estudios de historia del derecho o de la cultura jurídica cabe señalar que se ha insistido en la vinculación de Charcas a las dinámicas políticas del Río de La Plata, si bien se ha apuntado que fueron los procesos abiertos en tiempos de guerra y crisis los que permitieron adecuar la región y sociedad a la nueva legislación constitucional ${ }^{3}$. En el Perú ha predominado una óptica limeña, desde la que se ha llamado la atención sobre un núcleo de abogados que protagonizaron un cambio en su actuación profesional y en la esfera pública, abiertos a nuevas corrientes e influencias intelectuales, formados en el Real Convictorio de San Carlos ${ }^{4}$. Éstos asumieron un nuevo papel político protagónico cuando, en palabras de Mónica Ricketts, se ocuparon de «difundir información práctica, crear leyes y reformar el viejo orden... criticar autoridades, debatir sobre formas de gobierno, escribir panfletos subversivos e incluso a planear sublevaciones» convirtiéndose en la punta de lanza de la política moderna ${ }^{5}$.

Si bien en conjunto se ha avanzado en el análisis del Primer Liberalismo hispano ${ }^{6}$, casi desconocemos cuál fue el alcance del Segundo Liberalismo (1820-1824) en los amplios territorios que se mantuvieron bajo el dominio español: en la práctica las Audiencias del Cusco y Charcas, más las antiguas intendencias de Arequipa, Huamanga, Huancavelica y Tarma, que habían estado bajo la jurisdicción de la Audiencia de Lima al desaparecer de facto tras la ocupación de Lima por San Martín 7 . Fue un periodo en el cual Charcas lograría cierta autonomía ya que el jefe militar del Alto Perú concentró las competencias de jefe político de la provincia $^{8}$.

3 Soux, 2013. Irurozqui, 2003: 219-249. Roca, 2007. Thibaud, 2010.

${ }^{4}$ Espinosa, 1999. Valle, 2006. Ramos, 2003. Gálvez, 2002. Novoa, 2012. De la Puente, 2012. Quiroz-Pérez, 2005.

${ }^{5}$ Ricketts, 2013: 423.

${ }^{6}$ Peralta, 2009: 107-131.

7 En general la historiografía no ha prestado atención a los cambios que supuso en la cultura jurídica el Segundo Liberalismo, una muestra de ello en Gerke, 2012. De la Puente, 2012.

${ }^{8}$ En 1822 el auditor de guerra Francisco Entrambasaguas se dirigía al general y jefe del ejército del Alto Perú Juan Ramírez Ramírez recordándole su condición de «Jefe Superior de estas Provincias, por consiguiente penden de VS todas las resoluciones gubernativas y el arreglo en todos los ramos que componen el orden social y público de las Provincia sujetas a su inmediato mando». Ello suponía, en la práctica, que sumaba a sus competencias militares, las gubernativas sobre Charcas. No existen estudios para el caso peruano sobre la aplicación del modelo constitucional de gobierno de las provincias que suponía de facto la desaparición 
El protagonismo del derecho y los abogados en Cusco y La Plata entre Colonia y República

Cusco y La Plata fueron sedes de audiencia, obispado y universidad. Quizás por esa alta presencia institucional, ambas ciudades mantuvieron complejas pautas de sociabilidad, con una alta ritualidad en la esfera pública ${ }^{9}$. Los colegios, seminarios, universidades y academias les confirieron una impronta intelectual singular.

Ambas ciudades fueron el centro de amplios territorios de población mayoritariamente indígena, que se sublevó en varios episodios cruentos de ámbito local o general ${ }^{10}$. Sin embargo, su población urbana no sólo se mantuvo distante de la insurgencia, sino que en el caso de La Plata reforzó su identidad en oposición a la sublevación rural. Sin embargo la represión les afectó, sobre todo a partir del acuartelamiento de tropas regulares en ambas ciudades. El trato desconsiderado y despreciativo de éstas hacia los lugareños desencadenó fuertes protestas entre los vecinos de La Plata en 1781 y dos motines en 1782 y 1785. Sergio Serulnikov ha mostrado cómo tales episodios permitieron redefinir las alianzas de los distintos grupos urbanos chuquisaqueños, construyéndose nuevas pautas de sociabilidad, que tendieron a diluir las diferencias étnicas y estamentales y «la construcción de la imagen de la ciudad como sujeto de la historia y, por ende, actor político colectivo» ${ }^{11}$. Si bien en Cusco no llegó a tal punto el descontento, los pasquines y rumores de un posible levantamiento circularon profusamente en 1786, lo que determinó una contundente actuación de su intendente Benito de la Mata Linares ${ }^{12}$.

En ambas ciudades se organizaron movimientos juntistas, aunque en coyunturas distintas. En La Plata (1809) tomó la forma, ante el vacio real y en paralelo a la Junta Tuitiva de La Paz, de retroversión de la soberanía ${ }^{13}$. Marta Irurozqui ha demostrado, contra la versión generalizada, que la represión hispana fue más contundente con la Junta de La Plata que con la de La Paz. La Audiencia como institución defendió los derechos de los vecinos y del

de los Intendentes y su substitución, en el gobierno de las provincias, por el Jefe Superior y las Diputaciones Provinciales; y tampoco sobre su coincidencia con competencias militares. Sacado del documento: Sobre la formación de dos sala en las audiencias, Biblioteca Nacional de Perú, Lima (en adelante BNP), D 855.

9 Bridikhina, 2007.

${ }^{10}$ El estudio comparativo de referencia sigue siendo Lewin, 1972. Desde ópticas nacionales o de estudios regionales O'Phelan, 1985. Walker, 1999. Cajías, 2004. Serulnikov, 2006. Soux, 2010. Thompson, 2006.

${ }^{11}$ Serulnikov, 2008: 159; 2009: 439-469.

12 Torero, 1969-71: 402-9.

13 Rodríguez, 2005. 
territorio, ante los intentos de otras corporaciones e instancias administrativas de Lima o del Río de La Plata de incrementar su injerencia en la política de las provincias del Alto Perú. La Junta de 1809 habría sido una plataforma excepcional en defensa de los intereses regionales y su represión, si bien no fue de tipo penal, buscó cercenar su autonomía ${ }^{14}$.

En el Cusco la impronta de la audiencia, creada en 1788 como una de las medidas post-rebelión tupamarista, introdujo no sólo una instancia de intermediación judicial regional ${ }^{15}$, sino que también consolidó a un grupo de letrados, que en adelante tuvieron un papel protagónico en lo político. El Primer Liberalismo llevó a un largo conflicto entre las nuevas instituciones electivas liberales -ayuntamiento, diputación provincial- y la audiencia, destacando el papel de un grupo de abogados constitucionalistas, entre los que quizás el más destacado sería Rafael Ramírez de Arellano ${ }^{16}$, que a la postre serían desbordados ${ }^{17} \mathrm{o}$ se implicarían ${ }^{18}$ en el movimiento juntista que estallaría en agosto de 1814 .

En uno y otro lugar los abogados tomaron un protagonismo político en línea con lo apuntado por Mónica Rickkets para Lima, de agentes de una cultura política en el sentido moderno del término. La renovación jurídica tuvo lugar tanto en las audiencias, como en las cátedras. El fiscal de Charcas, Victorián de Villava, en la década de 1790 fue uno de los introductores de la escuela de juristas ilustrados napolitanos ${ }^{19}$. Manuel Lorenzo Vidaurre iniciaba desde su puesto de fiscal en el Cusco la que sería una de las trayectorias más singulares y de amplia trascendencia dentro de la judicatura peruana del siglo $\mathrm{XIX}^{20}$. Ambos debieron dejar un influjo no desdeñable en la práctica jurídica regional, si nos atenemos a que, en un sistema judicial en que las sentencias no debían fundamentarse, los dictámenes fiscales se constituyeron en el corpus de la argumentación procesal.

En ambas ciudades la expulsión de los jesuitas había dado lugar a cambios sustanciales en los estudios superiores. En Charcas, la Universidad y la Academia Carolina se propusieron y permitieron la formación de una generación

14 Irurozqui, 2011: 49-72.

15 Un balance de su incidencia en la población indígena en Walker, 1999: 95-112.

16 Ramírez de Arellano, Rafael, Proclama. Los verdaderos hijos de la nación, son los amigos de la Constitución, Lima, Imprenta de los Huerfanos, 1813.

${ }_{17}$ Peralta, 1996; 2010; 2012.

18 Relación de abogados a los que se prohibió su ejercicio hasta que no fueran depurados en nota del Regente, Cernadas, Bedoya, Cusco, 28 de abril de 1815 y de los rehabilitados, Revista del Archivo Histórico, III/3 (Cusco, 1952).

19 Portillo, 2009. Verdo, Morelli y Richard, 2012.

20 Peralta, 2007. Ramos, 2003. 
de abogados, quienes tuvieron un papel destacado en la circulación de ideas y saberes, en las luchas por la Independencia y los tempranos desarrollos constitucionales y de codificación en Bolivia y el Río de La Plata ${ }^{21}$, con un influjo no desdeñable en el Perú. En el caso del Cusco conocemos menos la labor y trascendencia intelectual de sus aulas universitarias, pero si nos atenemos al discurso iconográfico del cuadro Huerto Universitario de San Antonio Abad que nos ha legado, junto a otros ${ }^{22}$, y a la trascendencia sociopolítica de sus egresados, debemos presuponer que no se estuvo a la zaga de lo ocurrido en La Plata.

\section{La Justicia en el Perú bajo el liberalismo hispano (1812-14 y 1820-1824)}

La Constitución de 1812 sólo reconocía un único fuero ${ }^{23}$ y en consecuencia, sólo se contemplaba desarrollar un único código civil, criminal y de comercio para el conjunto de la Monarquía, aunque con la salvedad de mantener vigentes los fueros eclesiástico y militar. El sistema judicial colonial sufriría sustanciales cambios ya que bajo el Trienio Liberal fue estructurado piramidalmente de la siguiente forma: un Supremo Tribunal de Justicia con sede en la Corte, Audiencias, Jueces de Letras en los partidos, y alcaldes en los pueblos. Se posponía a una legislación posterior el determinar el número de Audiencias y sus jurisdicciones territoriales, que debían dividirse interna y proporcionalmente en diversos partidos judiciales ${ }^{24}$. Si bien al establecer juzgados primó la lógica territorial, subsistieron tribunales privativos en determinadas materias económicas, como fueron los Juzgados de Hacienda Pública, Consulados y Tribunales de Minería con competencias en temas fiscales, comerciales y minería. Su actuación se estableció con carácter provisional, hasta cuando las Cortes lo considerarán conveniente o legislaran sobre tal particular ${ }^{25}$. La aplicación práctica de la legislación liberal en la administración de justicia abrió un proceso tendente a respetar la estricta división de poderes y a reorganizar la administración del Estado según tal concepción legal, a excepción de los ayuntamientos locales, donde los alcaldes siguieron abarcando competencias judiciales y gubernativas ${ }^{26}$.

${ }^{21}$ Thibaud, 2010. De Gori, 2010; 2013.

22 Stastny, 1984. Villanueva, 1992. Mujica, 2002.

${ }^{23}$ Constitución de 1812, Título V, "De los Tribunales y de la administración de justicia en lo civil y en lo criminal" y Capítulo I, "De los Tribunales", art. 248.

${ }^{24}$ Ibidem, arts. 249, 250, 258, 259, 262, 272, 273 у 275.

25 Ibidem, Cap. II, art. XXXII.

${ }^{26}$ Sala i Vila, 2012: 423-450. 
El procedimiento judicial vendría definido por el Reglamento de las Audiencias y Juzgados de primera instancia de 9 de octubre de 1812. En Ultramar, los jefes políticos superiores -antiguos virreyes del ordenamiento Absolutista- perdieron toda competencia en temas de justicia, excepto en lo relativo al fuero militar, por lo que se suprimieron los cargos de asesores que les habían asistido en temas legales ${ }^{27}$. También se prohibió la intervención de las audiencias en asuntos gubernativos o económicos en sus respectivas demarcaciones $^{28}$, ordenándoseles la transferencia de los casos pendientes de resolución a las diputaciones provinciales de su demarcación. Los jueces de letras sólo podían intervenir en asuntos contenciosos de su partido, siéndoles vetada toda competencia de gobierno a partir de la constitución de los ayuntamientos ${ }^{29}$, suprimiéndose las subdelegaciones desde el momento que se hubieran fijado los nuevos distritos judiciales y se hubiera nombrado los respectivos jueces de letras ${ }^{30}$. Las audiencias mantuvieron una fuerte defensa corporativa de sus atribuciones exigiendo a las autoridades gubernativas que respetaran los preceptos legales y se nombrasen en los puestos de subdelegados de los respectivos partidos a abogados, conforme a sus atribuciones judiciales ${ }^{31}$.

El Reglamento de 1812 fijó el número de audiencias, entre tanto no se llevaba a cabo la división provincial del territorio español que establecía el artículo 11. En el Perú reconoció las de Lima y Cusco, más Charcas en el Alto Perú, adscribiéndoles el mismo territorio jurisdiccional vigente hasta ese momento y manteniendo la misma sede ${ }^{32}$. Según esta norma, la Audiencia Nacional de Lima se compondría de un regente, doce ministros togados y dos fiscales, organizados en tres salas -dos civiles y una criminal-, integradas cada una de ellas por cuatro jueces. Las Audiencias Nacionales de Cusco y Charcas, a su vez, estarían formadas por un regente, nueve ministros y dos fiscales, con una sala de cuatro ministros para las causas civiles y criminales

27 Reglamento de las Audiencias y Juzgados de primera instancia de 9 de octubre de 1812 , Cap II, art. XXXI. www.congreso.es/docu/blog/decretos/P-0007-00217.pdf. Fecha de consulta: 29 de noviembre de 2015.

28 Ibidem, Cap. I, art. XIV.

29 De Jorge García de la Torre al Regente, Madrid, 14 de marzo de 1820, orden al margen, Cusco a 27 de setiembre de 1820, Archivo Regional del Cusco, Cusco (en adelante ARC), Cédulas Reales, leg. 3.

30 Reglamento de las Audiencias y Juzgados de primera instancia de 9 de octubre de 1812 , Cap. II, arts. LXIV, VIII y XXX.

31 Autos de la Audiencia del Cusco de 15, y 17 de noviembre de 1821 y 28 de junio de 1822. ARC, Intendencia, Gobierno, Pedimentos, leg. 242, 1814-24.

32 Reglamento de las Audiencias y Juzgados de primera instancia de 9 de octubre de 1812 , Cap. I De las Audiencias, art. I. 
en apelación vistas en segunda instancia y otra de cinco para las causas en tercera instancia ${ }^{33}$.

Se encargaba a las diputaciones provinciales, de acuerdo con la audiencia respectiva, el que llevaran a cabo una nueva división y demarcación de las provincias en partidos judiciales ${ }^{34}$. Los partidos debían ser proporcionalmente iguales, pero en ultramar se debía procurar que todo territorio de más de 5.000 vecinos tuviera al menos un juez letrado, si bien se considerarían de forma excepcional los partidos preexistentes cuyo número de vecinos fuera menor del señalado por ley y que no pudieran agregarse a otros por su «localidad, distancia o extensión ${ }^{35}$. En cada partido, se nombraría un número de jueces letrados proporcional al de vecinos, tanto en las ciudades, como en los partidos densamente poblados, pudiéndose agregar a tal fin pueblos cercanos cuando ello facilitara el acceso a la justicia de sus habitantes ${ }^{36}$. En el caso del Perú, la diputación provincial limeña inició el estudio de la demarcación judicial territorial en 1814, durante el gobierno del virrey José de Abascal ${ }^{37}$, un proceso que quedó trunco tras el retorno al Absolutismo en 1814.

En la primavera austral de 1820 el virreinato del Perú volvió a los dictados constitucionales gaditanos ${ }^{38}$. Se abría una etapa que se prolongaría hasta mediados de 1824, en la cual en las ciudades y pueblos de la retaguardia bélica, se impusieron los principios liberales de la Constitución de 1812 y los decretos de Cortes de la etapa 1810-14 y 1820-22, no así los de la fase exaltada del Trienio Liberal, cuando el Perú dejo de tener comunicación continua con la península. Sin embargo la realidad quedó profundamente alterada a raíz de la ocupación de Lima por el general San Martín y del repliegue del virrey La Serna hacia la sierra.

Entre las contingencias imprevistas, se produjo la inhabilitación de facto de la Audiencia Nacional de Lima, que entre otras consecuencias supuso el cercenar el sistema jerárquico judicial. Conscientes de sus implicaciones, la Audiencia Nacional del Cusco invitó al virrey a trasladarse a la antigua capital de los Incas, esgrimiendo, entre sus razones, dos que eran de gran calado en

${ }^{33}$ Ibidem, Cap. I, arts. VI y VII.

${ }^{34}$ Ibidem, Cap. II, "De los Jueces letrados de partido", art. I. Las diputaciones provinciales también eran competentes, de acuerdo con las Audiencias, para fijar el personal subalterno de los jueces de letras, Ibidem, cap. II, art. VI.

${ }^{35}$ Ibidem, Cap. II, art. III y IV.

${ }^{36}$ Ibidem, Cap. II, art. V.

${ }^{37}$ Los informes han sido publicados en Castillo et al., 1994: 397-504.

38 Jorge García de la Torre al Regente, Madrid 14 de marzo de 1820, con anotación de haberse recibido en Cusco el 21 de octubre de 1820, si bien se estaba cumpliendo desde 15 de octubre de 1820, ARC, Cedulas Reales, leg. 3, 1820. 
cuanto a la organización de la justicia en el Perú. En primer lugar se referían a la necesidad de resolver el derecho de apelación respecto las Audiencias de Cusco y Charcas y los jueces de las provincias anteriormente sujetas a la jurisdicción limeña -Arequipa, Tarma, Huamanga y Huancavelica-. En segundo lugar, y no menos importante, llamaban la atención sobre la necesidad de contar con un tribunal superior competente en dirimir las dudas de interpretación del nuevo entramado jurisdiccional constitucional, que generaba una situación dominada por

las dificultades diariamente mayores con que las Audiencias tropiezan en la precisa esfera de sus atribuciones constitucionales, ya por las dudas imprescindibles de un sistema legislativo todo nuevo, ya por las contradicciones de unos, e ineptitud de otros, o ya por los respectos que debe los Magistrados al tiempo más crítico y delicado que jamás vieron sus ojos ${ }^{39}$.

Para resolver la precaria situación descrita por la Audiencia cusqueña, el virrey La Serna optó por la solución provisional de reordenar el mapa judicial, entre las dos únicas audiencias subsistentes, la de Cusco y la de La Plata, siendo la primera declarada como Territorial, adscribiéndosele las provincias de Tarma, Huancavelica, Huamanga y Arequipa, antes dependientes de la de $\mathrm{Lima}^{40}$, y la de Chiloé a partir de mayo de $1823^{41}$.

Las contingencias bélicas y el relativo aislamiento del Perú realista cortaron cualquier posibilidad de cubrir las vacantes de ministros (antiguos oidores ${ }^{42}$ ) y jueces, ya que ello era potestad del Rey a propuesta del Consejo de Estado. Tal contingencia obligó a tomar medidas excepcionales para que las audiencias pudieran seguir funcionando, sobre todo para cubrir las vacantes de ministros, con el nombramiento de jueces interinos.

${ }^{39}$ La Audiencia del Cusco al Virrey, Cusco, 5 de noviembre de 1821, en Colección Documental de la Independencia del Perú, 1973: 57-60.

${ }^{40}$ Expediente sobre que quedan agregadas al territorio de esta Audiencia Nacional las Provincias de Tarma, Guancavelica, Guamanga y Arequipa mientras la ocupación de Lima por los disidentes, 8 de enero de 1822. José de la Serna a la Audiencia Nacional de esta Capital, Cuzco, 5 de enero de 1822, resolución circulada en dichas provincias en 3 de diciembre de 1821, ARC, Intendencia, Gobierno, Pedimentos, leg. 242, 1814-24.

${ }^{41}$ Expediente sobre entablar constitucionalmente en la provincia de Chiloé la administración judicial civil y criminal, 1 de mayo de 1823, ARC, Corte Superior de Justicia, Archivo Administrativo, libro 36, libro 1 del despacho diario de la Audiencia Constitucional del Cuzco en su Primera Sala.

${ }^{42}$ En el texto utilizaré la terminología coetánea para referirme a los jueces: oidores en los periodos absolutistas y ministros en los constitucionales y, en ocasiones, los términos genéricos de jueces y jueces interinos (conjueces en la documentación). 
Abogados, Jueces y fiscales en el contexto del Segundo Liberalismo hispano

La Audiencia Nacional de Charcas se vio obligada a buscar alternativas que permitieran su viabilidad dada la carencia de jueces y, a la vez, adecuarse a los principios organizativos constitucionales y al Reglamento de 1812, sobre todo en lo relativo a asegurar el derecho de apelación de los litigantes o sujetos penales en su provincia de residencia. Ello dio lugar a que se incoase un expediente iniciado en febrero de 1821 y resuelto en setiembre de 1822 , en el que se cruzaron consultas, opiniones y decisiones de las Audiencias de Charcas y Cusco y de los virreyes/jefes políticos de la provincia del Perú -Joaquín de la Pezuela (1816-21) y José de la Serna (1821-24)- y del Alto Perú -general Juan Ramírez-, que emitieron sendas resoluciones apoyados en los dictámenes de sus auditores de guerra y fiscales.

A inicios de la década de 1820, la Audiencia Nacional de Charcas se hallaba en plena crisis, integrada sólo por dos oidores, Manuel José de Reyes y José Félix Campoblanco, y un fiscal, Juan Antonio Zabala. En ese contexto debía adecuarse dicho tribunal al espíritu constitucional y por ello en febrero de 1821 elevaron sendas peticiones firmadas una por el pleno de la Audiencia y otra a título personal por el regente Reyes. En ambas se exponía la imposibilidad práctica, dada su limitada composición, de organizar las salas previstas en la legislación liberal (artículos 21, 30, 37, 38 del Reglamento de 1812). Un problema que se agudizaba cuando era altamente improbable el nombramiento y traslado de nuevos jueces desde la península, junto a la dificultad de poder nombrar jueces interinos, debido a la carencia de togados en su distrito, agudizada por la implicación de la mayor parte de ellos en el nuevo régimen político representativo, sobre todo al haber sido electos en cargos concejiles en los ayuntamientos constitucionales. Concluían que todo ello «ofrece graves dificultades el que se establezca el orden constitucional» ${ }^{43}$. El liberalismo gaditano establecía un mínimo de tres jueces para formar sala o dictar sentencia, que debían ampliarse a cinco cuando se fuera a imponer una pena corporal. Ante la carencia de jueces en Charcas, se recurrió a la solución adoptada durante el Primer Liberalismo (1812-14). Entonces se incorporó al fiscal en funciones de juez, a los agentes fiscales en las de fiscal y a distintos abogados en ejercicio como conjueces. Sin embargo, seguía sin resolverse como organizar la $2^{\text {a }}$ Sala tal y como ordenaban los artículos 18 , 39 y 40 de Reglamento de 1812.

La Audiencia Nacional de Charcas solicitó al virrey Pezuela una alternativa viable para adecuarse a los dictados constitucionales, y ofrecía tres

${ }^{43}$ Consultas de 7 y 12 de febrero de 1821, BNP, D 855. 
posibles soluciones. La primera pedía el mantenimiento del sistema preconstitucional, con la impartición de justicia en una única instancia, a la que se podrían incorporar los conjueces letrados necesarios, escogiéndose con preferencia para ello al juez de letras de la ciudad y los agentes fiscales. Pero como consideraban conveniente actuar de acuerdo a las normas de la Carta Magna, y por tanto, asegurar la actuación en dos salas, la segunda propuesta era tendente a organizar la sala de apelaciones con la presidencia del ministro José Félix Campoblanco e integrada por tres conjueces y la otra sala por el regente Manuel José de Reyes, completada por el fiscal y tres conjueces. La tercera solución abogaba por convertir la Audiencia «inmediata» en tribunal de apelación, aunque había que valorar si ello contravenía los artículos 12 y 63 del Reglamento de 1812 y los altos costos que supondría para los litigantes.

El virrey Pezuela remitió la consulta al general Juan Ramírez, en su doble calidad de jefe militar y jefe político superior de la provincia del Alto Perú. Éste, pediría un dictamen a su auditor de guerra, Francisco Entrambasaguas ${ }^{44}$, quien aconsejó formar la Segunda Sala con los dos jueces titulares y el fiscal y derivar las apelaciones a la Audiencia Nacional del Cusco. Ésta era una alternativa que estimaba acorde con el artículo 268 de la Constitución, que disponía que los recursos de nulidad, de no poderse fallar por falta en el número de jueces preceptivos, fueran resueltos en distinta audiencia; algo que, a su parecer, no contravenía el artículo 63 del Reglamento de 1812. Descartaba las otras propuestas, una por inconstitucional y la otra por la dificultad de costear cinco conjueces en tiempos de gran penuria. El general Ramírez se conformaría con el dictamen en 21 de mayo de 1821.

En junio de 1821, Manuel José de Reyes mostraba su descontento ante tal decisión, alegando que no se basada en la «concurrencia de votos facultativos», sino sólo en el parecer del auditor de guerra. Sabedor de que la Audiencia Nacional del Cusco había elevado una consulta en parecidos términos a los suyos, solicitaba la transferencia del expediente de nuevo al virrey, para que éste consultara a «otras corporaciones y concurrentes» y se buscara una fórmula de completar los jueces necesarios en ambos tribunales. Ante ello, el general Juan Ramírez recabó un nuevo dictamen al auditor de guerra Entrambasaguas en setiembre de 1821. Éste insistía que su decisión, lejos de ser fruto de cierta animosidad o de una reflexión apresurada, debía valorarse como «prudente, acertada y única acaso adaptable a las últimas circunstancias» y acorde a lo propuesto, entre otras opciones, por el propio Regente. Por ello se reafirmaba en su opinión, y si bien reconocía los considerables costos que

\footnotetext{
${ }^{44}$ Juan Ramirez, Cuartel general de Arequipa, 2 y 21 de mayo de 1821, BNP, D 855.
} 
comportaría a los litigantes al tener que sustentar su apelación en el Cusco, peor sería la no resolución de las causas en grado de súplica por no poderse formar la preceptiva sala. Con todo, recomendaba elevar consulta al virrey, en cuanto se recuperara la ciudad de Lima y concluyera la campaña militar contra los insurgentes ${ }^{45}$.

El regente Reyes recurrió al por entonces nuevo virrey José de la Serna a fines de diciembre de 1821, con la prevención textual de que «en materias de Justicia le es privativo todo lo concerniente a su más recta y pronta administración». Le pedía una solución basada en los pareceres de magistrados o si fuera conveniente de fiscales, ya que éstos eran competentes en «examinar y pedir el cumplimiento de la Ley». Desde la posición de autonomía institucional impuesta por la división de poderes, lamentaba que Ramírez se hubiera conformado sólo con el parecer del auditor de guerra y ordenado que las causas en apelación fueran derivadas al Cusco. Tal decisión, era según Reyes, «opuesta a las literales disposiciones constitucionales, y a su espíritu, cuya transgresión no es permitida, ni por el Rey, ni a las mismas Cortes Soberanas, y mucho menos a cualquiera otra Autoridad; y que también lo es degradante sobremanera de la Audiencia y de sus Ministros», por cuanto se «les quiere someter y subordinar a la del Cuzco, dándole una superioridad que nunca ha tenido». Asimismo, recordaba que la Constitución -arts. 247, 262 y $163-$ y el Reglamento de 1812 -arts. 2 y 63 - establecían que todo español tenía derecho a ser juzgado, en lo civil y criminal, por un tribunal competente y dentro de su territorio de residencia. Además una audiencia sólo podía intervenir en las causas de su demarcación, negando el artículo 12 del Reglamento la superioridad de una sobre otras. Y si bien era cierto que tal solución se propuso desde el propio tribunal, al mismo tiempo se argumentaron las causas por la que se consideraba legalmente improcedente. Se reafirmaba en la viabilidad de formar las dos salas fijadas por ley con los dos ministros existentes, el juez de letras y conjueces nombrados entre abogados de probidad. Para ello partía del presupuesto de que las Leyes de Indias no habían sido revocadas $\mathrm{y}$, en consecuencia, una audiencia subsistía aunque sólo estuviera compuesta por un único oidor,

de lo contrario sería dejar los pueblos en anarquía, sin administrar justicia, impugnes a los delitos y espuesta la propiedad y la seguridad individual con manos del más fuerte ${ }^{46}$.

45 Dictamen de 22 de setiembre de 1821, Auto de conformidad de Juan Ramírez de 25 de setiembre de 1821 y Remisión del expediente a La Serna en 30 de setiembre de 1821, BNP, D 855.

${ }^{46}$ Acuerdo de la Audiencia de Charcas de 7 de marzo de 1821, BNP, D 855. 
En efecto, para preservar su entidad y asegurar el funcionamiento institucional, una audiencia podía nombrar jueces natos o suplentes entre los jueces de letras de la capital o entre los abogados en ejercicio, tal como se establecía en el artículo 30 del Reglamento de 1812. Una medida a la que la Audiencia de Charcas había recurrido desde 1817, sin que jueces o abogados nombrados interinamente exigieran emolumento alguno, contentándose todos con el honor de tal cargo y «el mérito y servicio que hacen en obsequio de la Nación y del Público» ${ }^{47}$.

La Serna, escuchó en parte el alegato, y remitió el expediente a la Audiencia Nacional del Cusco para que informaran convenientemente. El fiscal Martín José Mujica el 21 de enero de 1822 hacia recuento de como se había intentado resolver la carencia de oidores en el Cusco. En octubre de 1820, «dos días antes de publicarse y seis de jurarse aquí la Constitución restablecida» se pidió al virrey que nombrase o trasladase jueces suficientes para poder constituir la sala que permitiera resolver los procesos judiciales en grado de apelación, o en la terminología de la época en tercera instancia. La Audiencia Nacional del Cusco el 13 de enero de 1821 y su fiscal el 30 de marzo de1821 consultaron, ya en plena vigencia de la Constitución, como debían proceder para poder constituir de forma provisional la Segunda Sala, a la espera que el Rey nombrara los «Ministros de la dotación constitucional». La situación se había agravado al incorporarse las provincias hasta entonces sujetas a la Audiencia de Lima, dado el mayor número de causas a tratar y resolver en apelación. Apuntaban que el problema era una reedición del que se planteó durante el Primer Liberalismo, cuando el virrey Abascal concluyó que el asunto excedía a sus competencias, puesto que, según el artículo 171 de la Constitución, los ministros de las audiencias sólo podían ser nombrados por el Rey a propuesta del Consejo de Estado y por consiguiente que la distancia y las contingencias de la guerra evidenciaban un problema irresoluble en las audiencias de ultramar.

Permítasenos aquí una breve digresión para referir lo acaecido entre 1812 y 1814, que ayude a entender a cabalidad el trasfondo del asunto. La Audiencia Nacional del Cusco decidió en marzo de 1813 nombrar jueces interinos al oidor honorario y diputado electo a Cortes (1811), Manuel Galeano, junto a Pedro López de Segovia y los doctores Luis Astete y Miguel Vargas. Sin embargo no tuvieron como afrontar su salario y el virrey Abascal fue dando largas a sus peticiones, a lo que se añadió que jamás se dotó fondo alguno para cubrir dichos emolumentos. Ello determinó que seis meses después de

\footnotetext{
${ }^{47}$ Manuel José de Reyes a José de la Serna, La Plata, 27 de diciembre de 1821, BNP, D 855.
} 
asumir sus cargos, López de Segovia y Vargas dimitieron de sus cargos, entre tanto Galeano dejó sin más de asistir a las sesiones del tribunal ${ }^{48}$.

En 1822, el fiscal Mujica recordaba que la necesidad de cubrir las plazas de jueces nunca se había resuelto convenientemente, a pesar de haber sido tratado en las Cortes en 1813, unos hechos y debates que conocía de primera mano en su calidad entonces de diputado en Cádiz por Huamanga. Apuntaba que éstas, tras escuchar el informe del secretario del Despacho de Gracia y Justicia, Antonio Cano, el 28 de septiembre de 1813 o analizar los días 28 y 29 de noviembre de 1813 la consulta del Consejo de Estado a la Regencia, acordaron abrir consultas para conocer dónde y cuántos magistrados faltaban en las audiencias de ultramar y al mismo tiempo recabar información de distintas instituciones -audiencias, ayuntamientos, jefes superiores y universidadessobre que sujetos cumplían los requisitos - conducta y actitud- establecidos en el Reglamento de 1812. Sin embargo y según Mujica, no se acordó provisión alguna relativa al modo en que debían cubrirse las vacantes de magistrados, fuera del marco estrictamente constitucional o del Reglamento de 1812. Y apostillaba que si en la etapa 1812-14 tal vacío legal creó dificultades, peor era la situación que se vivía en 1822 cuando no era previsible que juez alguno nombrado desde la península pudiera emprender el viaje al Perú a causa de la guerra y el bloqueo naval. Una realidad a la que se sumaba, a su parecer, «la rareza de profesores dignos» y la carencia de fondos para costear sus servicios. Por todo ello, sólo cabía elevar consulta al virrey, cuya resolución debía ser comunicada públicamente por bando.

El Real Acuerdo se reunió en el Cusco el 24 de enero de 1822, como consecuencia del decreto de la propia Audiencia del 21 del mismo mes y cuando un nuevo factor añadía dificultades a la situación. El día anterior había fallecido el ministro Bartolomé Mosquera, por lo que el tribunal quedaba sólo constituido por Pedro Antonio Cernadas, Presidente Regente, Santiago Corbalán y José Darcourt, lo que hacía imposible constituir la 2a Sala también en el Cusco. El que se cerrara la posibilidad de revisar las causas judiciales en apelación, llevaba al tribunal a afirmar que con ello "se desplomaría el orden político», la quietud devendría en discordias, sin que se pudiera limitar el despotismo y arbitrariedad de los jueces inferiores. Para prevenir tal contingencia se proponía al virrey dirimir las causas vistas en segunda y tercera instancia según las «Leyes Antiguas», e incorporar para ello al tribunal los jueces interinos necesarios.

${ }^{48}$ La Audiencia Nacional del Cuzco sobre el nombramiento de conjueces para la formación de la Segunda Sala y de jueces de letras, 1813, BNP, D 404. 
Para resolver la situación, La Serna optó el 7 de febrero de 1822 por trasladar al fiscal de Charcas, Juan Antonio Zavala, a la Audiencia Nacional del Cusco en calidad de ministro ${ }^{49}$ y permitir que se nombraran jueces «eventuales», escogidos entre los abogados en ejercicio en la ciudad con el fin de completar los cinco ministros preceptivos, según lo dispuesto en el reglamento de 1812 . En Charcas proponía nombrar un fiscal y dos conjueces, sin preveer constituir la $2^{\text {a }}$ Sala, al no poderse afrontar los sueldos de los jueces. En virtud de tal propuesta, ese mismo día, reunidos en Acuerdo, los ministros Cernadas, Corbalán, Darcourt y el fiscal Mujica optaron por regular una suerte de reglamento de funcionamiento interno provisional de la Audiencia Nacional del Cusco. Sucintamente se acordó que Cusco y La Plata sólo tendrían una sala y un fiscal, compuesta aquella por el Regente-Presidente o en su defecto por el decano, más tres ministros o jueces permanentes. El virrey, a propuesta de las audiencias, cubriría las vacantes de ministros bien con magistrados refugiados en la ciudad o con aquellos provistos para otras audiencias. En cualquier caso, su sueldo se asignaría con cargo a la Hacienda pública. Las apelaciones y causas criminales debían ser vistas al menos por cinco jueces, para lo cual se incorporaría al tribunal el fiscal y el juez de letras de la capital o un abogado elegido a pluralidad de votos; los recursos de nulidad debían ser remitidos a una audiencia distinta. Ante tal decisión, la Audiencia Nacional de Charcas, las diputaciones provinciales del Cusco y Charcas y los Jefes Políticos Superiores podían alegar lo que considerasen conveniente. Se intentaría, cuando fuera posible, informar al Rey y justificar las medidas tomadas para que no colapsara la administración de justicia, se encarecía que se ordenara la provisión de las magistraturas vacantes.

El virrey La Serna comunicó su aprobación el 12 de febrero de 1822 e impuso tal reglamento a la Audiencia Nacional de Charcas. En la práctica, abolía lo aprobado tres meses antes por ésta en acuerdo de justicia del 12 de diciembre de 1821. Entonces de forma mayoritaria el regente-presidente Manuel José Reyes, el decano José Félix de Campoblanco, el fiscal Juan Antonio Zavala, el juez de letras de la ciudad Manuel Sánchez de Velasco y los agentes fiscales resolvieron formar las dos salas, una presidida por el decano y la otra por el Regente, incorporando respectivamente al juez de letras y al fiscal, además de los jueces interinos necesarios en cada una de ellas. En las causas vistas y sentenciadas por el juez de letras de Potosí, se integraría en la $1^{\text {a }}$ Sala al fiscal y en la $2^{\mathrm{a}}$ al regente; en las relativas a Censos, en la $1^{\mathrm{a}}$ al fiscal y en

${ }^{49}$ Lo sustentaba en que éste había solicitado permiso para casarse con la hija del Regente y no convenía que tras ello continuara en La Plata. Algo que podemos considerar, visto lo visto, como una de tantas argucias en el caso. 
la $2^{\mathrm{a}}$ al regente; en las de Bienes de Difuntos, en la $1^{\mathrm{a}}$ al decano y en la $2^{\mathrm{a}}$ al regente; por último el decano y el juez de letras verían las causas de vista y el regente y el fiscal las de revista. El Tribunal pleno de ministros y jueces interinos se formaría los lunes y jueves para resolver lo conveniente y asignar autos a quienes pretendieran examinarse para obtener el título de abogado.

La imposición de una normativa de funcionamiento interno al tribunal charqueño dio lugar a una reunión en acuerdo de justicia el 7 de marzo a la que asistieron el regente, el decano y el fiscal, junto al juez de letras y dos agentes fiscales, Casimiro Olañeta, Manuel Sánchez de Velasco y Manuel José Antequera. Los reunidos partieron de la siguiente premisa:

Estando encargada la administración de justicia a las Audiencias privativamente sin que el Rey ni las Cortes puedan entrometerse en ella, le parece no estarse en el caso de admitir Reglamentos particulares que son prohibidos por la Constitución y mucho más aquellos que se oponen a ella ${ }^{50}$.

El acta recogía las intervenciones de cada uno de ellos relativas a los dos supuestos de la orden virreinal: 1) si procedía o no derivar las causas en apelación al Cusco y 2) como cubrir las vacantes de ministros y fiscal. En el primer supuesto las voces fueron unánimes en considerar el acuerdo del 12 de diciembre de 1821 fiel a la Constitución y al Reglamento de 1812, muy al contrario de lo propuesto por la Audiencia Nacional del Cusco. Negaban a ésta competencia alguna sobre la de Charcas, recalcando que ni tan siquiera habían solicitado sus «sufragios consultivos», puesto que su petición se había dirigido exclusivamente al virrey. Asumían que aquella no había impuesto su reglamento, antes bien se trataba de una decisión unilateral del virrey La Serna, que buscaba uniformizar los procedimientos en ambos tribunales. Sin embargo el tribunal defendía a ultranza su autonomía, como manifestaba textualmente uno de los agentes fiscales:

No consideraba facultades en ningún otro Tribunal que no sean las Cortes o el Rey para revocar las Leyes fundamentales como se revocan por el Reglamento remitido por el Virrey y formado por la Audiencia del $\mathrm{Cusco}^{51}$.

En lo relativo a suplir las vacantes de jueces, se aceptaba la intervención virreinal, reconociéndole a dicha autoridad competencia en ello derivada sólo de las «actuales circunstancias de la América».

\footnotetext{
${ }^{50}$ Acuerdo de la Audiencia de Charcas, 7 de marzo de 1821, BNP, D 855.

${ }^{51}$ Idem.
} 
En una nueva reunión, efectuada el 11 de marzo, acordaron desconocer la orden virreinal y mantener vigente el procedimiento aprobado en 12 de diciembre de 1821. Basaron su posición en que el artículo 262 de la Constitución establecía que las causas civiles y criminales debían resolverse y fenecer «dentro del territorio de cada Audiencia». Con ello se podía completar el número de jueces que fijaba el artículo 7 capítulo 1 del Reglamento de 1812, sin transgredir el artículo 264 de la Constitución, que impedía a un mismo juez intervenir en distintas instancias de vista y revisión de una misma causa, ni el 375, que «prohibía toda alteración, adición o reforma» de la Carta Magna. Siguiendo el formato adoptado en el Cusco y en atención de ciertas consideraciones posteriores, optaron por redactarlo de nuevo, diferenciando el texto por capítulos: la $1^{\text {a }}$ Sala se formaría con el decano, el juez de letras de la capital y un letrado como juez interino y la $2^{\mathrm{a}}$ con el regente más los jueces suplentes necesarios, escogiéndose para ello con preferencia a los agentes fiscales. Además, para evitar que un juez emitiera su voto en instancias distintas, se modificaría la composición de las salas, así en los casos que no se pudiera alcanzar los tres votos conformes, deberían nombrarse dos letrados para dirimirlas. Si bien era cierto que no se podía formar sala sin al menos tres ministros -artículo 37, capítulo $1^{\circ}$ del Reglamento de $1812-$, cabía considerar que «conservándose la esencia y facultades de una Audiencia en un solo señor Ministro, según la ley del Reino» y atendiendo al Decreto del 11 de abril de 1813 podría formarse sala con un Ministro y el resto con jueces interinos. Por último, los recursos de nulidad de otra Audiencia serían dirimidos por el regente, decano y jueces y serían contempladas una serie de casuísticas particulares -causas criminales con pena corporal, suspensión o separación de jueces inferiores, recursos de fuerza...-, que intentarían resolverse alternando los ministros y jueces interinos, para que no coincidiera un mismo parecer y voto emitido en distintas salas.

La Audiencia Nacional de Charcas remitió al virrey La Serna copia de las actas de las reuniones y acuerdos tomados el 7 y 11 de marzo, encareciéndole «se sirva tomar el medio más análogo a las actuales circunstancias y mejor cumplimiento de las Leyes Constitucionales». Éste remitió el documento al fiscal Mujica para que emitiera su dictamen, que lleva fecha de 31 de marzo de 1822. Visto en acuerdo de justicia por el Regente, Corbalán, Darcourt y el fiscal el 2 de mayo, se abstuvieron de refutar los argumentos del tribunal charqueño y se reafirmaron en considerar prioritario uniformizar los procedimientos de ambas audiencias, para lo que debía preferirse el reglamento adoptado en el Cusco, puesto que ya había sido aprobado y ratificado por el virrey. En consecuencia el virrey La Serna en 13 de mayo exigió a la Audiencia Nacional de Charcas que adoptara el reglamento cusqueño, anunciándoles que 
no toleraría una actuación descoordinada entre ambas instancias. Además les recordaba que debían sujetarse a su autoridad:

esta en el orden de este tribunal se sujete a mis determinaciones gubernativas, porque soy la única autoridad superior en estos países, y de ellos sólo tengo que responder al gobierno de la Nación ${ }^{52}$.

E insistía en que la Constitución y leyes vigentes le facultaban para tomar cuantas providencias fueran necesarias para «la salvación del Estado». La respuesta vino firmada en 12 de junio por Manuel José de Reyes y José Félix Campoblanco. En ella le comunicaban que no podían aceptar tales órdenes, puesto que podrían conllevar en el futuro la nulidad de lo actuado, más las consecuencias que se derivarían de actuar al margen de los dictados constitucionales. Textualmente le escribieron, que en el supuesto de aceptar sus órdenes, ello les podría acarrear graves consecuencias, y textualmente le recalcaban:

sino fuesen terribles las penas que le impone el nuevo sistema que nos rije, y la antigua Ley del Reino le obligara a Suplicar hasta tercera vez de aquellas en que sea necesario cubrirse de toda responsabilidad ${ }^{53}$.

La Serna les respondió el 30 de junio que si la voluntad de la audiencia charqueña era conservar la armonía y respetar la autoridad superior debía haber puesto en práctica lo que se les ordenó, puesto que la responsabilidad era del virrey y, en ningún caso de la audiencia. Les recordaba que «no cedo a persona alguna en amar el sistema constitucional» y que su actuación venía determinada por la «crisis presente». En suma les dijo taxativamente que, para cortar de raíz sus representaciones, su orden valía por las tres prescritas en la Ley Antigua del Reino y que debían ceñirse a lo dispuesto en el reglamento del Cusco.

El 15 de julio los ministros de Charcas claudicaban e integraban al tribunal en calidad de jueces interinos al juez de letras de Chuquisaca y dos abogados, Manuel Sánchez de Velasco y Manuel María de Urcullu, mientras tanto el cargo de fiscal sería ejercido por uno de los agentes fiscales, si bien éstos podrían ser llamados a ejercer como jueces cuando fuera necesario. El 19 de julio se quejaron al virrey del procedimiento y términos en que éste les imponía su autoridad «puesto que se conceptúan adeptos a la Ley y a VE mismo cuando más empeño pongan en reclamar sus deberes».

\footnotetext{
${ }_{52}^{5}$ La Serna a la Audiencia de Charcas, 13 de mayo de 1822, BNP, D 855.

${ }^{53}$ Manuel José de Reyes y José Félix de Campoblanco a La Serna, La Plata, 12 de junio de 1822, BNP, D 855.
} 
El 8 de agosto de 1822 falleció Manuel José de Reyes ${ }^{54}$ y por lo tanto sólo quedaba un único magistrado en activo en la Audiencia Nacional de Charcas, el ministro Campoblanco. La noticia llegó al Cusco junto a la petición de los agentes fiscales para que se nombraran conjueces permanentes. La Serna lo consultó al fiscal Mujica y al auditor de guerra José María Lara ${ }^{55}$. El primero se mostró inicialmente favorable a nombrar jueces interinos, ya que sólo así se podría salvar dicha Audiencia de su inhabilitación por falta de ministros y retomar su actividad. Lara adujo que o bien se cerraba la audiencia y se incorporaban sus provincias a la jurisdicción del Cusco, o, para evitar consecuencias indeseables en una coyuntura ya de por si compleja, se nombraban jueces de probada trayectoria y «amor a las nuevas instituciones». El criterio de los ministros de la Audiencia Nacional del Cusco fue que no podía desaparecer el alto tribunal de Charcas por su dilatada jurisdicción territorial y que para asegurar su viabilidad debían nombrarse con carácter provisional tres jueces, sin esperar para ello su propuesta. Los elegidos debían cumplir como requisitos «adhesión a la Constitución, literatura, buena educación y moralidad» ${ }^{56}$. En consecuencia, el virrey La Serna, luego que el auditor de guerra Lara se amoldara a la propuesta del fiscal ${ }^{57}$, nombró el 10 de noviembre tres jueces interinos con destino a la Audiencia Nacional de Charcas: como decano a Lorenzo Fernández de Córdova, relator jubilado de dicha audiencia; junto a Sebastián Yrigoyen, juez de letras provisional de la provincia de Cochabamba, y a Gabriel José de Palacios, catedrático de Prima de cánones de la Universidad de San Francisco Xavier. Al mismo tiempo remitía al secretario de Estado y del Despacho de Justicia sendas solicitudes para que José Félix de Campoblanco fuera elevado a Regente ${ }^{58}$ y José María Lara a ministro de dicha audiencia ${ }^{59}$.

En febrero de 1824, el general y jefe del ejército del Alto Perú, Pedro Antonio de Olañeta ${ }^{60}$, tras enfrentarse al virrey La Serna e imponer la derogación de la Constitución, decidió retrotraer la organización de la Audiencia de

${ }^{54}$ Oficio de Rafael Manoso, Jefe Político de Charcas, al Virrey, La Plata, 9 de agosto de 1822 y Certificado de José Cabero, abogado y escribano de Cámara, La Plata, 9 de agosto de 1822, BNP, D 855.

${ }^{55}$ Dictámenes de Martín José Mujica de 16 de agosto y 5 de setiembre de 1822 y de José María Lara de 5 de setiembre de 1822, BNP, D 855.

${ }^{56}$ Regente, Darcourt y Zavala, 5 de setiembre de 1822, BNP, D 855.

57 Dictamen de José María Lara de 7 de setiembre de 1822, BNP, D 855.

58 Carta del virrey José de La Serna a Felipe Benicio Navarro, secretario de Gracia y Justicia, Cusco, 10 de setiembre de 1822, Archivo General de Indias, Sevilla (en adelante AGI), Lima, 762.

${ }^{59}$ Memorial del Dr. D. José María de Lara, Cusco, 30 de setiembre de 1822, AGI, Indiferente, 1570.

${ }^{60}$ Sobre la práctica política de Pedro Antonio de Olañeta ver Peralta e Irurozqui, 2014: 44-88. 
Charcas «al mismo pie y forma que tenía en el año 1819», cuando el virrey Pezuela había nombrado, ante la falta de jueces, en tal cargo a Manuel José de Antequera y de fiscal a Casimiro Olañeta. En consecuencia cesó a los conjueces nombrados por La Serna, substituyéndolos por Manuel José de Antequera, José Santos Cabero y Manuel María Urcullu. Ante el hecho que su sobrino Casimiro Olañeta actuaba por entonces de secretario personal suyo, situó en el cargo de fiscal a Mariano del Callejo ${ }^{61}$. El general Jerónimo Valdez, en su alegato contra Olañeta, dejó constancia de que tales disposiciones fueron fruto de una alianza del general absolutista con los sectores independentistas de Charcas, cuando

colocó en la Real Audiencia de Charcas Jueces nombrados por sí con los sueldos que le señaló su capricho, escogiendo para estos destinos los hombres más notables de insurgentes, como Antequera, Orcullo, su sobrino Casimiro, Callejo y Cavero, por cuya circunstancia habían sido perseguidos por diferentes autoridades, despojando así de sus destinos a los que obtuvieron consideraciones por Abascal, Goyeneche y otros ${ }^{62}$.

Si aceptamos la versión de Valdez, el general Olañeta con tal decisión devolvía la Audiencia al estado de cosas anterior a que La Serna ordenara su subordinación a la del Cusco. En la práctica devolvía a dicha institución su plena autonomía y restablecía en sus puestos a aquellos que habían sido nombrados jueces interinos o fiscales por los propios ministros, escogidos de entre los abogados en ejercicio en Charcas.

\section{LA EMERGENCIA DE LOS ABOGADOS: DE ASESORES INSTITUCIONALES A JUECES Y POLÍTICOS}

¿Quién era quién en el agrio enfrentamiento que se vivió entre los virreyes Pezuela y La Serna, los jefes del ejército del sur, generales Juan Ramírez y Pedro Antonio de Olañeta, y las Audiencias de Cusco y Charcas? Los cuatro primeros son de sobras conocidos, si bien contamos con mayores aportaciones historiográficas sobre su actuación militar ${ }^{63}$, que sobre su labor gubernativa.

${ }^{61}$ Pedro Antonio de Olañeta a Mariano Fermín Ojeda, La Plata, 15 de febrero de 1824, en Torata, 1898, IV: 185-6.

62 Valdez, 1973: 358.

${ }^{63}$ En general han primado balances sobre la estrategia militar de los virreyes Pezuela o La Serna, obviando en parte su labor gubernativa, en tal sentido Ortemberg y Sobrevilla, 2011. Albi, 2009. Moreno, 2010. 
Me interesa sin embargo destacar el papel de los asesores letrados y de los magistrados, fiscales y jueces de letras en todo el proceso descrito.

El regente-presidente de la Audiencia Nacional de Charcas, Manuel José de Reyes y Borda (Santiago de Chile, 1754-La Plata, 1822), estudió leyes en San Felipe, fue asesor de la intendencia del Cusco, oidor de Audiencia de Buenos Aires (1805-1810) y de Charcas (1810-1822). Durante la revolución de mayo de 1810 en Buenos Aires se mantuvo leal al virrey Cisneros, luego de la cual fue trasladado a La Plata. El ministro decano José Félix Campoblanco era ya miembro de la Audiencia en 1809 y participó en la Junta de Chuquisaca, de la cual salió indemne sin mayores consecuencias en el devenir de su carrera en la judicatura, continuando sin mayores problemas en su puesto de oidor/ ministro hasta 1824. Según Roca, favoreció el cabildo abierto de La Plata del 12 de noviembre de 1809 , en cuyo trascurso se decidió un acercamiento a Buenos Aires y mantener la independencia respecto los intentos anexionistas del Perú ${ }^{64}$. A ello hay que sumar, que supo controlar los resortes del nuevo escenario político liberal como muestra que fuera escogido como elector del partido de Charcas en el marco de las elecciones legislativas a Cortes de $1822^{65}$.

Entre otras medidas, la Constitución de 1812 comportó la desaparición del cargo de asesor legal, de resultas de la pérdida por parte de los funcionarios de las competencias judiciales a raíz de la aplicación estricta del principio liberal de separación de poderes. Sin embargo las contingencias de la guerra justificaron que se concentrara en la figura del Jefe Superior de la Provincia el mando militar y, aprovechando tal resquicio, La Serna, Ramírez y Olañeta, en su calidad de jefes superiores de las provincias del Perú el primero y del Alto Perú los otros dos, apoyaron sus decisiones en los dictámenes de sus auditores de guerra, cargo que fue ocupado respectivamente por José María de Lara, Francisco Entrambasaguas y Ramón María de Urcullu.

La Serna nombró, tras consultar a la audiencia cuzqueña, como asesor y auditor de guerra a José María de Lara, con competencias en los «negocios de gobierno» y en los asuntos militares y criminales respectivamente ${ }^{66}$. Lara (Asunción, 1767 - La Paz, 1836), formado como abogado en la Academia Carolina y recibido como tal en la Audiencia de Charcas, fue oidor honorario de la Audiencia del Cusco, regidor antiguo del ayuntamiento de Potosí, y

\footnotetext{
${ }^{64}$ Roca, 2007: 202.

${ }^{65}$ Solicitud del puesto de Regente de José Félix Campoblanco, La Plata, 10 de agosto de 1822, AGI, Lima, 762.

${ }^{66}$ Copia del título y aceptación del señor Asesor y Auditor General del Virreynato don José María de Lara, tomado del libro de Real Hacienda. Se le nombró en 14 de enero de 1822 , juró en 25 de junio de 1822 y en 10 de agosto de 1822 se le fijó un sueldo de 3.000 pesos anuales, BNP, D 1013.
} 
diputado electo a Cortes por Potosí en $1814^{67}$ y $1821^{68}$. Integró la comisión negociadora con las Provincias libres del Río de La Plata a principios de 1821 y de motu propio negoció con el guerrillero José Miguel Lanza en abril de $1822^{69}$. Francisco Entrambasaguas y Montalvo era natural de La Plata e hijo de comerciante, alumno de la Academia Carolina, abogado y catedrático de Prima de Teología, fue teniente asesor interino de la intendencia de la Plata (1818) y juez interino de la Audiencia de Charcas ${ }^{70}$. Manuel María de Urcullu (La Plata 1785), estudió leyes en la universidad de San Francisco Xavier y la práctica de abogado en la Academia Carolina, el gobierno de Buenos Aires le nombró fiscal de la cámara de apelaciones de Charcas en 1813, por lo que según su propio testimonio, «había sufrido persecuciones de parte de los realistas» ${ }^{71}$, como apuntamos fue fiscal y juez interino entre 1822-24 y auditor de guerra del general Olañeta en 1824. Por último, José Joaquín Casimiro Olañeta y Güemes (1795-1860) era sobrino del realista y absolutista Pedro Antonio Olañeta, de quién fue su secretario durante sus últimas campañas militares en 1824 y principios de 1825. Doctorado en leyes en la universidad charqueña en 1815 y alumno de la Academia Carolina, actuó de agente fiscal en la Audiencia de Charcas, siendo elevado a fiscal interino a raíz del traslado del fiscal Zavala a la Audiencia del Cusco, y como tal defendió acaloradamente la autonomía de la Audiencia de Charcas respecto al Perú.

En el Cusco destacaron por sus argumentos asumidos bien ante la Audiencia o ante el virrey, el fiscal Mujica y el auditor de guerra Lara. Martín José Mujica (Rexil, Guipuzcoa, 1774-Cusco, 1841) se trasladó a Córdoba de Tucumán con su tío Miguel Antonio de Mújica ${ }^{72}$, estudió leyes en la Universidad San Antonio Abad del Cusco, obteniendo el grado de licenciado y doctor en la universidad de San Cristóbal de Huamanga y el de abogado ante la Audiencia de Lima (1802) ${ }^{73}$. En Huamanga desempeñó sucesivamente los cargos de protector de naturales, asesor del cabildo, promotor fiscal de Real Hacienda,

${ }^{67}$ Irurozqui, 2003: 246.

${ }^{68}$ Archivo del Congreso de Diputados de España, Madrid, Serie Documentación Electoral, 9, n. ${ }^{\circ} 32$.

${ }^{69}$ Roca, 2007: 487-99.

${ }^{70}$ Carta $n^{\circ} 160$ del virrey Joaquín de la Pezuela a Juan Esteban Lozano de Torres, secretario de Gracia y Justicia, Lima, 10 de setiembre de 1818, AGI, Lima, 758, N.6.

${ }^{71}$ Urcullu, 1855: 135.

${ }^{72}$ Licencia de pasajero a Indias de Miguel Antonio de Mújica con sus sobrinos Martín José y José Antonio de Mújica a Buenos Aires, 13 de julio de 1789, AGI, Contratación 5533, N.2, R.37.

${ }^{73}$ Grado de Abogado de Martín José Mújica, 1802, Archivo General de la Nación, Lima, Perú (en adelante AGN), Grados de Abogados, leg.4, cuaderno nº 253. 
procurador general de la Universidad de San Cristóbal. Electo diputado por Huamanga, se incorporó a las Cortes el 1 de abril de 1814, participando en varias comisiones y siendo electo secretario el 1 de mayo del mismo mes. Tras ser disueltas las Cortes y luego de una orden expresa de Fernando VII del 17 de junio de 1814 que permitía a los diputados americanos seguir en la Península y defender los intereses de sus provincias, persistió por resolver las demandas regionales incluidas en las instrucciones que le fueron conferidas por los cabildos de Huamanga y Huancavelica ${ }^{74}$. Nombrado fiscal de la Audiencia del Cusco en 13 de diciembre de 1815, ejerció el cargo desde el 24 de octubre de 1817 hasta fines de 1824, actuando entre 1817 y mediados de 1818 , y de forma intermitente, de juez interino. Su defensa a ultranza del constitucionalismo merecería que el propio virrey La Serna le recomendara en 1822 por su «adhesión a las nuevas instituciones» ${ }^{75}$.

Tras la Independencia, el único que abandonaría los Andes fue Francisco Entrambasaguas, quien en 1828 era fiscal de la Audiencia de Filipinas y posteriormente ocuparía la plaza de fiscal (hasta 1840) y luego de ministro (1843-44) del Tribunal Supremo de España ${ }^{76}$. Los otros abogados mencionados fueron actores destacados en la construcción del Estado en el Perú y Bolivia, asumiendo cargos en los distintos poderes y actuando algunos de ellos de activistas políticos de primera fila. En 1825 José $\mathrm{M}^{\mathrm{a}}$ Lara fue asesor de Agustín Gamarra y el primer fiscal de la Corte Superior de Justicia del Cusco, creada el 16 de febrero de $1825^{77}$. Posteriormente se acercaría a Andrés de Santa Cruz, quién le nombraría ministro de Hacienda de Bolivia en torno a 1830. Martín José Mujica regresó a Ayacucho de donde era originaria su esposa. A pesar de ser marginado inicialmente de la judicatura al ser considerado «acérrimo realista ${ }^{78}$, lograría ya en enero de 1826 ser nombrado asesor legal de la municipalidad de Ayacucho y tiempo después se incorporaría como vocal en la corte

${ }^{74}$ La documentación relativa a su actuación en defensa de los intereses de Huamanga y Huancavelica se halla dispersa en AGI, Lima 613 y 1358; Indiferente 1355.

${ }^{75}$ La Serna al Secretario de Estado y del Despacho de Gracia y Justicia, Cusco, 10 de setiembre de 1822, AGI, Lima 762.

${ }^{76}$ Nombramiento de Caballero Gran Cruz de la Orden de Isabel la Católica a Francisco Entrambasaguas, Auditor de Guerra, Archivo Histórico Nacional, Madrid, (AHN), Estado, 3013, exp. 33-8. Expediente de clasificación de jubilación de Francisco Entrambasaguas, AHN, FC-M ${ }^{\circ}$ Hacienda, 3013, exp.165. AHN, Fiscal de Hacienda y Fondos Contemporáneos, I, 4396, 2420.

77 Acuerdos de la Audiencia Nacional del Cuzco desde el restablecimiento de la Constitución en el año de 1820, ARC, Corte Superior de Justicia, Archivo Administrativo, libro 28.

${ }^{78}$ Razón de los abogados que tienen fijada su residencia en el Departamento de Ayacucho en oficio de Francisco Valdivieso al decano de la corte del distrito judicial del departamento, Lima, 1 de febrero de 1827, AGN, Corte Superior de Justicia de Lima, 387, Administrativo, 1822-29. 
de justicia del Cusco (1833-41), cargo que ocuparía hasta su fallecimiento ${ }^{79}$. Desde Ayacucho actuaría en la compleja recomposición regional de la temprana república, apoyando en 1825 que el departamento dejara de estar ligado en lo judicial a Lima y pasara a depender de la jurisdicción del Cusco, alegando la mejor comunicación y fluidas relaciones existentes entre ambas provincias.

Casimiro Olañeta y Manuel María Urcullu fueron jueces en la primera Corte Superior de Justicia de Bolivia que se creó a principios de 1825 bajo los dictados de Antonio José de Sucre con las mismas atribuciones y jurisdicción de la Audiencia de Charcas $^{80}$. Urcullu sería diputado en varias legislaturas $(1825,1831,1837)$, magistrado y presidente de la Corte Suprema de Justicia $(1827,1835,1837)$ y autor de textos políticos y jurídicos ${ }^{81}$. Ambos fueron diputados en la Asamblea Constituyente boliviana, reunida en Chuquisaca, que tuvo que definir la posición de Charcas ante las pretensiones sobre el territorio de argentinos y peruanos. Según el testimonio del propio Manuel María Urcullu, en la cámara de representantes se recibieron dos comunicaciones contrapuestas. Una con fecha de 9 de mayo de 1825 del Congreso de Buenos Aires en la que se les dejaba a su libre albedrío para decidir su destino. La otra del 16 de mayo de 1825, remitida desde Arequipa por Simón Bolívar en la que se les indicaba que no acordasen nada entretanto el Congreso peruano no se reuniera como tenía previsto en 1826 y en el ínterin el Alto Perú quedaba adscrito al gobierno peruano. Ante la opción transmitida por Bolívar, que en la práctica les disolvía como entidad territorial autónoma dentro de la nueva república del Perú, la Asamblea declaró la independencia de Charcas, nombrando una diputación integrada por Casimiro Olañeta, José María Mendizábal e Hilarión Fernández para responder a Bolívar que

ningún derecho tenía el Perú sobre estas provincias para sancionar o no sus determinaciones, porque si algunas veces las ocupó por la fuerza a nombre del Rey, había sido constantemente repelido por la misma fuerza, hasta haber sacudido en el año próximo pasado toda intervención suya en sus negocios ${ }^{82}$.

Era el último acto de una larga lucha por la autonomía y luego la independencia de las gentes y los territorios bajo la jurisdicción de la Audiencia

${ }^{79}$ Flórez, [1932]; 1840.

${ }^{80}$ Decreto de Antonio José de Sucre de 27 de abril de 1825, Colección oficial de leyes, decretos, ordenes de la Republica Boliviana, años 1825 y 1826, La Paz, Artística, 1827. La integraban además Mariano Serrano, Mariano Ulloa, Leandro Uzin, Mariano Guzmán y Eusebio Gutiérrez.

${ }^{81}$ Calvo y Urcullu, 1834. Urcullu, 1855.

${ }^{82}$ Urcullu, 1855: 155-6. 
de Charcas, cuyos hitos se situaron en el movimiento juntista de La Plata de 1809 y, como hemos relatado, en la resistencia de la Audiencia por ser subordinada a la del Cusco entre 1821-24.

\section{CONCLUSIONES: «EL TIEMPO DE LOS ABOGADOS» ${ }^{83}$}

En 1809 la Junta de La Plata actuó ante un rey ausente, mientras que en 1821-22 la Audiencia Nacional de Charcas lo hizo en una coyuntura en la que el monarca en la práctica, y debido a la guerra y el bloqueo de comunicaciones, no podía manifestarse en ningún sentido. El conflicto derivado de las dificultades de aplicar los dictados constitucionales en el poder judicial y en el que intervinieron en mayor o menor medida los virreyes Pezuela y La Serna, los jefes militares del Alto Perú, Ramírez y Olañeta y las Audiencias de Charcas y Cusco encubría un largo litigio en defensa de la entidad y autonomía de las provincias del Alto Perú. En 1821, como hemos narrado, la Audiencia Nacional de Charcas, apoyada en los dictados liberales y el principio de separación de poderes, volvía a insistir en la defensa de su autonomía, mostrándose una vez más como la institución que representaba la identidad provincial.

En el seno de los movimientos juntistas, las audiencias o sus oidores/ ministros cobraron protagonismo como consecuencia tanto de considerarse depositarias de la soberanía ante la ausencia real, como al asumir su papel previsto en la legislación indiana de audiencias gobernadoras en situaciones de vacío de poder. La transición del Antiguo Régimen colonial al constitucionalismo liberal dio lugar a que el espacio sobre el que ejercía jurisdicción la audiencia fuera reconocido con entidad territorial propia, léase provincia, y con derecho a representación política y autogobierno ejercido por una institución creada de nuevo cuño, cual fue la diputación provincial. La decisión de La Serna de imponer la supremacía y el carácter territorial de la Audiencia Nacional de Cusco sobre la de Charcas fue percibida como una decisión que quebraba el principio de autonomía jurisdiccional de las provincias, y por ende de la audiencia. Los dos únicos jueces subsistentes en el tribunal con sede en La Plata, lejos de dejarse llevar por el infortunio de los tiempos y de permitir el receso temporal o definitivo de la audiencia o el mal menor de su subordinación, asumieron la defensa de la independencia institucional, aliándose para ello con sectores de la abogacía local.

Fuera por opción o por necesidad, las Audiencias Nacionales del Cusco y La Plata, junto a los jefes políticos de las provincias -el virrey La Serna y

${ }^{83}$ Sala i Vila, 2014. 
los jefes militares del Alto Perú- incorporaron respectivamente como jueces interinos y auditores de guerra a abogados originarios y formados en las provincias bajo control español, cuya trayectoria sería clave en la judicatura y la construcción nacional en los departamentos del sur del Perú y en Bolivia. Se trató de un salto cualitativo en el protagonismo profesional y político de los abogados surgidos de las universidades de La Plata, Cusco o Huamanga. Clément Thibaud ha señalado que los abogados egresados de la charqueña Academia Carolina dirigieron hasta 1809 su actuación profesional bien al desempeño de la abogacía, o bien ocuparon cargos que podrían considerarse menores dentro del entramado de la administración colonial -asesores de cabildos, protectores de naturales,... Sin embargo hemos constatado el salto cualitativo que se impuso en el tiempo en que se produjo una breve pero radical aplicación de la Constitución de 1812 (1812-14 y 1820-24) y durante el largo ciclo bélico que afectó el sur del virreinato del Perú y el Alto Perú desde al menos 1809. Entonces, ante la absoluta carencia de jueces que pudieran asegurar la administración cabal de justicia, los abogados locales coparon de forma mayoritaria los puestos vacantes de jueces, más todos los cargos públicos que debían ser desempeñados preceptivamente por abogados -auditores de guerra, asesores de ayuntamientos, secretarios de diputaciones provinciales...- y la mayoría de las representaciones electivas -diputados a Cortes y Diputaciones Provinciales, más alcaldías y regidurías municipales ${ }^{84}$. Se trató del asalto final de las elites locales a un sistema colonial, que durante el Reformismo borbónico y tras desaparecer la venalidad de los cargos de la administración, había vetado la entrada de sectores criollos en las distintas instancias estatales. El camino quedó trazado. Primero los abogados del Perú y Charcas escalaron posiciones de jueces interinos o auditores de guerra, siendo electos varios de ellos diputados provinciales o a Cortes del Reino y, tras la Independencia, vertebraron los poderes judicial y legislativo, además de asumir distintos cargos en el ejecutivo y mantener una presencia activa en la esfera pública. En sus actuaciones políticas, influidos por su formación jurídica inspirada en la ilustración napolitana y los presupuestos liberales y republicanos, actuaron asumiendo como eje central de su activismo la argumentación y el debate de ideas, mientras que su labor parlamentaria les permitió intervenir en la redacción de las nuevas leyes y en su codificación. Y todo ello sucedía mientras se dirimía en el campo de batalla el destino de los territorios andinos. Se trató de una guerra cruenta, que coexistió con un complejo y cambiante entramado de alianzas y contra alianzas, en la que se dirimió, entre muchos

${ }^{84}$ Tal afirmación responde a los resultados de la investigación sobre las prosopografías de los representantes locales y provinciales analizados en Sala i Vila, 2011; 2014. 
otros conflictos, el devenir del diseño territorial-provincial de los Andes postcoloniales en el que desempeñó un lugar clave las reivindicaciones y horizontes de las elites locales.

El conflicto independentistas se enclaustró entre 1821-25 en las provincias del sur del Perú y en Charcas, que mantenían reivindicaciones de autonomía regional respecto Lima y las corporaciones centralistas. El traslado de La Serna a Cusco fue de la mano de la búsqueda de alianzas en sectores sureños, que le apoyaran en sostener su proyecto político liberal y en financiar los costes bélicos. Cusqueños, huamanguinos, charqueños entraron a formar parte de sus más estrechos colaboradores en su obra de gobierno -Lara como auditor de guerra y asesor, Mújica en su calidad de fiscal, entre otros-, junto a sectores de comerciantes regionales -Juan José Olañeta, hermano del general Olañeta y diputado de comercio del Cusco, Pedro Zorraquín en Huamanga y Lucas de la Cotera en Arequipa- en pos de una mayor autonomía ante el monopólico y centralista Consulado limeño. Por su parte el general Pedro Antonio de Olañeta basó, en el caso que hemos analizado, su campaña militar en el Alto Perú en sumar a su proyecto a los sectores de las elites profesionales urbanas representadas por actores como Manuel $\mathrm{M}^{\mathrm{a}}$ Urcullu o Casimiro Olañeta. Éstos se distanciaron del virrey La Serna cuando priorizó los intereses cusqueños frente a los charqueños, un factor determinante en el que persistieron tras la Independencia cuando fueron abanderados en la defensa de la identidad de Charcas y de su autonomía política respecto al Perú o Buenos Aires.

Cada audiencia examinaba e integraba a sus propios abogados. Cabe presuponer que tal realidad confirió características y entidad propia a los abogados que ejercieron en las jurisdicciones del Cusco o de Charcas. Éstos, más allá de su desempeño de juristas, actuaron en defensa de las reivindicaciones de cada una de sus regiones, frente a los intereses contrapuestos de otros grupos de regiones aledañas. Hasta el presente, no hemos comparado el imaginario regional defendido por cada uno de los grupos de presión, pero sabemos bien que su actuación fue decisiva en los movimientos juntistas de 1808-9 o la del Cusco de 1814 y en los primeros congresos constituyentes.

Y nos queda apuntar una última llamada de atención sobre lo narrado. Las Audiencias del Cusco y Charcas se vieron obligadas a asumir un papel destacado, tanto en la búsqueda de soluciones que permitieran poner en práctica los dictados y el espíritu de la Constitución de 1812 en el terreno judicial, como en la provisión de los puestos vacantes y necesarios para asegurar la tutela judicial de los habitantes de su jurisdicción, sin que éstos tuvieran que recurrir a otras instancias fuera de sus demarcaciones. En todo el proceso se esgrimió la primacía de la Constitución y del Reglamento de 1812 sobre cualquier otra legislación anterior, pero cuando convino se remitieron a las leyes antiguas para 
no desaparecer como tribunal de justicia. Un indicador del complejo proceso de adecuación de la legislación indiana a los modelos constitucionalistas y codificaciones liberales, con largas coyunturas de coexistencia y tensiones entre ambas fuentes de derecho, que merece una investigación atenta.

\section{BIBLIOGRAFÍA}

Albi, Julio, El último virrey, Madrid, Ollero y Ramos Eds., 2009.

Bridikhina, Eugenia, Theatrum mundi. Entramados del poder en Charcas colonial, La Paz, Plural/IFEA, 2007.

Cajías, Fernando, Oruro 1781: sublevación de indios y rebelión criolla, La Paz, IFEA, 2004.

Calvo, Mariano Enrique y Urcullu, Manuel María, Observaciones sobre la reforma que debe hacerse del Código Penal Boliviano, La Paz, Imprenta del Colegio de las Artes, 1834.

Castillo, Francisco et al., Las Cortes de Cádiz y la Imagen de América, Cádiz, Universidad de Cádiz, 1994.

Colección Documental de la Independencia del Perú, vol. XXII, Lima, Comisión Nacional del Sesquicentenario de la Independencia del Perú, 1973.

De Gori, Esteban, "La universidad de Charcas: teoría y acción política", Revista de Historia de la Educación Latinoamericana, (Tunja, 2010): 169-190.

De Gori, Esteban, "Narraciones compartidas: imaginarios políticos entre Charcas y Buenos Aires (de las reformas borbónicas al proceso juntista)", Procesos: revista ecuatoriana de historia, 37 (Quito, 2013): 57-79.

De la Puente, José, "Entre dos mundos: juristas peruanos del tiempo de la Independencia", José María Pérez Collados y Samuel Rodríguez Barbosa (eds.), Juristas de la independencia, Madrid, Marcial Pons, 2012: 583-614.

Espinosa, Grover Antonio, "La reforma de la educación superior en Lima: el caso del Real Convictorio de San Carlos", Scarlett O'Phelan (comp.), El Perú en el siglo XVIII. La Era Borbónica, Lima, PUCP-IRA, 1999: 205-241.

Flórez, Pedro G., Guía de forasteros del Cuzco para el año 1833, Cuzco, Imprenta pública por Evaristo González, [1932].

Flórez, Pedro G., Calendario y guía de forasteros de la República peruana para el año de 1841, Lima, Imp. de Instrucción Primaria por Félix Moreno, 1840.

Gálvez, José Francisco, "Las bases del Estado peruano y el proceso de independencia", Madrid, tesis doctoral, Universidad Complutense, 2002. 
Gerke, Carlos, "Bolivia. Los juristas de la independencia”, José María Pérez-Collados y Samuel Rodríguez Barbosa (eds.), Juristas de la independencia, Madrid, Marcial Pons, 2012: 65-102.

Irurozqui, Marta, "El sueño del ciudadano. Sermones y catecismos políticos en Charcas tardocolonial”, Mónica Quijada y Jesús Bustamante (coords.), Élites intelectuales y modelos colectivos: mundo ibérico (siglos XVI-XIX), Madrid, CSIC, 2003: 219-249.

Irurozqui, Marta, "Soberanía y castigo en Charcas. La represión militar y judicial de las juntas de La Plata y La Paz, 1808-1810", Revista Complutense de Historia de América, 37 (Madrid, 2011): 49-72.

Irurozqui, Marta, “A resistir la conquista'. Ciudadanos armados en la disputa por la revolución. Bolivia, 1839-1842”, Flavia Macías (coord.), “Milicias, levantamientos armados y construcción republicana en Hispanoamérica. Estudios y propuestas para el siglo XIX", Boletín del Instituto de Historia Argentina y Americana Dr. Emilio Ravignani, 42 (Buenos Aires, 2015): 60-91.

Lewin, Boleslao, La rebelión de Tupac Amaru y los orígenes de la emancipación americana, La Habana, Editorial Ciencias Sociales, 1972.

Moreno, Iñigo, José de La Serna último virrey español, Madrid, Akrón, 2010.

Mujica, Ramón, “El arte y los sermones”, Ramón Mujica et al., El Barroco Peruano, Lima, Banco de Crédito, 2002: 219-313.

Novoa, Mauricio, "Juristas, eclesiásticos y oficiales del rey: los abogados de la Audiencia de Lima antes de la Independencia”, Carmen Mc Evoy, Mauricio Novoa y Elías Palti (eds.), En el nudo del Imperio. Independencia y democracia en el Perú, Lima, IEP-IFEA, 2012: 369-394.

Ortemberg, Pablo y Sobrevilla, Natalia, "Edición y estudios introductorios", Joaquín de la Pezuela, Compendio de los sucesos ocurridos en el ejército del Perú y sus provincias (1813-1816), Santiago de Chile, Centro de Estudios Bicentenario, 2011.

Peralta, Víctor, "Elecciones, constitucionalismo y revolución en el Cusco, 1809-1815", Revista de Indias, 56/206 (Madrid, 1996): 99-131.

Peralta, Víctor, "Ilustración y lenguaje político en la crisis del Mundo Hispánico. El caso del jurista limeño, Manuel Lorenzo de Vidaurre", Nuevo Mundo Mundos Nuevos [En línea], Coloquios, Puesto en línea el 12 febrero 2007, consultado el 23 julio 2013. URL: http://nuevomundo.revues.org/3517; DOI: 10.4000/nuevomundo.3517.

Peralta, Víctor, "La transformación inconclusa. La trayectoria del liberalismo hispánico en el Perú (1808-1824)”, Ayer, 74/2 (Madrid, 2009): 107-131.

Peralta, Víctor, La independencia y la cultura política peruana, 1808-1821, Lima, IEP-Fundación MJ Bustamante de la Fuente, 2010. 
Peralta, Víctor, "La participación popular en las juntas de gobierno peruanas de Huánuco (1812) y Cuzco (1814)", Pilar Cagiao, y José Ma Portillo, (coords.), Entre imperio y naciones: Iberoamérica y el Caribe en torno a 1810, Santiago de Compostela, Universidad de Santiago de Compostela, 2012: 317-340.

Peralta, Víctor e Irurozqui, Marta, "Locos adoradores de Fernando. Pedro Antonio de Olañeta frente al liberalismo hispánico en Charcas (1821-1825)", Anuario del Archivo y Biblioteca Nacionales de Bolivia, 20 (Sucre, 2014): 44-88.

Portillo, José $\mathrm{M}^{\mathrm{a}}$, La vida atlántica de Victorián de Villava, Madrid, Mapfre/Doce Calles, 2009.

Quiroz-Pérez, Lissell, "Les magistrats péruviens au XIXe siècle. Des hommes de pouvoir au cœur de la transition politique (1808-1825)", Cahiers de Amériques Latines, 50 (París, 2005): 107-125.

Ramos, Carlos, "El orbe jurídico ilustrado y Manuel Lorenzo de Vidaurre" y "Legislación, abogados y exégetas", Historia del derecho civil peruano. Siglos XIX y $X X$, vol. I y IV, Lima, PUCP, 2003.

Ricketts, Mónica, "De la palabra a la acción: Oradores, editores, abogados y conspiradores en el virreinato del Perú, 1780-1808", Revista de Indias, 73/258 (Madrid, 2013): 399-430.

Roca, José Luis, Ni con Lima ni con Buenos Aires. La formación de un Estado nacional en Charcas, La Paz, Plural eds./IFEA, 2007.

Rodríguez O., Jaime, Revoluciones, Independencia y las nuevas naciones de América, Madrid, F. Mapfre-Tavera, 2005.

Sala i Vila, Núria, "El Trienio Liberal en el Virreinato peruano: los ayuntamientos constitucionales de Arequipa, Cusco y Huamanga, 1820-1824", Revista de Indias 71/253 (Madrid, 2011): 693-728.

Sala i Vila, Núria, "Justicia conciliatoria durante el liberalismo hispano en el Perú: el caso de Huamanga", Anuario de Estudios Americanos, 69/2 (Sevilla, 2012): 423-450.

Sala i Vila, Núria, “Quedarán ya para el polvo y el olvido’: las elecciones a diputados a las Cortes españolas en el Perú, 1810-1824”, Ascensión Martínez Riaza (ed.), La independencia inconcebible. España y la "pérdida" del Perú (1820-24), Lima, IRA-PUCP, 2014: 213-286.

Sala i Vila, Núria, "Saberes, ciencias y política en la formación del Estado en el Perú decimonónico", Lima, IEP, 2016 (en prensa), ponencia presentada al Seminario 'El Estado como institución en América Latina y el Perú', Instituto de Estudios Peruanos (IEP) - Universidad Antonio Ruiz de Montoya, Lima, 2014. 
Serulnikov, Sergio, Conflictos sociales e insurrección en el mundo colonial andino: El norte de Potosí en el siglo XVIII, México, FCE, 2006.

Serulnikov, Sergio, “'Las Proezas de la Ciudad y su Ilustre Ayuntamiento': Simbolismo político y política urbana en Charcas a fines del siglo XVIII", Latin American Research Review, 43/3 (Pittsburg, 2008): 137-165.

Serulnikov, Sergio, "Crisis de una sociedad colonial. Identidades colectivas y representación política en la ciudad de Charcas (siglo XVIII)", Desarrollo Económico, 48/192 (Buenos Aires, 2009): 439-469.

Soux, Ma Luisa, El complejo proceso hacia la independencia de Charcas (18081826). Guerra, ciudadanía, conflictos locales y participación indígena en Oruro, La Paz, Plural eds., 2010.

Soux, $\mathrm{M}^{\mathrm{a}}$ Luisa, Estudios sobre la Constitución, la ley y la justicia en Charcas, entre Colonia y República. Aproximaciones desde la historia del derecho, La Paz, IEB, 2013.

Stastny, Francisco, "La universidad como claustro, vergel y árbol de la ciencia. Una invención iconográfica de la Universidad del Cuzco", Anthropológica, 2/2 (Lima, 1984): 105-167.

Thibaud, Clément, La Academia Carolina y la independencia de América. Los abogados de Chuquisaca (1776-1809), Sucre, Editorial Charcas Fundación, 2010.

Thompson, Sinclair, Cuando sólo reinasen los indios. Política aymara en la era de la insurgencia, La Paz, Aruwiyiri-Muela del Diablo, 2006.

Torata, conde de, Documentos para la historia de la guerra separatista del Perú, vol. IV, Madrid, Imprenta de la viuda de M. Minuesa, 1898.

Torero, Carmen Fanny, "Establecimiento de la Audiencia del Cusco", BIRA, 8 (Lima, 1969-71): 374-522.

Urcullu, Manuel María, Apuntes para una historia de la revolución del Alto-Perú, hoy Bolivia, Sucre, Imprenta de López, 1855.

Valdez, Jerónimo, "Exposición que dirige al rey don Fernando VII el mariscal de campo... sobre las causas que motivaron la pérdida del Perú", Colección Documental de la Independencia del Perú, tomo XXII, v. $3^{\circ}$, Lima, Comisión Nacional del Sesquicentenario de la Independencia del Perú, 1973.

Valle Rondón, Fernando, "Teología, Filosofía y Derecho en el Perú del siglo XVIII: Dos reformas ilustradas en el Colegio de San Carlos de Lima (1771 y 1787)", Revista Teológica Limense, XL/3 (Lima, 2006): 337-382.

Verdo, Geneviève; Morelli, Federica y Richard, Élodie (eds.), Entre Nápoles y América. Ilustración y cultura jurídica en el mundo hispánico (siglos XVIII y XIX), Medellín, La carreta histórica, 2012. 
Villanueva, Horacio, La Universidad Nacional de San Antonio Abad del Cusco, Cusco, s.n., 1992.

Walker, Charles F., De Tupac Amaru a Gamarra. Cusco y la formación del Perú Republicano, 1780-1840, Cusco, CBC, 1999.

Fecha de recepción: 22 de abril de 2015.

Fecha de aceptación: 27 de enero de 2016.

\section{"Law, Power and Freedom" on the Battles for the Jurisdictional Autonomy between the Courts of Cusco and Charcas (1820-1825)}

As of 1820 and after the invasion of San Martin, the Peruvian judicial system had to adapt to the de facto disappearance of the High Court of Lima, as well as to the model that had been designed by the Constitution of 1812 and the Magistrate and High Court Code of 9 October, 1812. This paper analyzes said process and the ensuing tension resulting from the High Courts of Cusco and Charcas having to solve procedural problems, but paying special attention to the debates and actors, especially lawyers, that constituted the Hispanic judicial culture during the Three-Year Liberal Period in the viceroyship of Peru, supposing that said reality extended to the national construction of Peru and Bolivia.

KeY words: Three-Year Liberal period; Peru; Judicial culture; High Court of Cusco; High Court of Charcas. 